\title{
DIEZ AÑOS DEL BRICS: CRISIS DE HEGEMONÍA OCCIDENTAL Y CONSTRUCCIÓN DE UN ORDEN MUNDIAL MULTIPOLAR
}

Juan Sebastián Schulz'

Entre el 14 y el 16 de noviembre de 2019 se llevó a cabo la XI Cumbre del BRICS en Brasilia, lo que significó no sólo el décimo aniversario del nacimiento formal del grupo, sino también la onceava Cumbre de mandatarios consecutiva desde la primera reunión en Ekaterimburgo, Rusia, allá por 2009. En este marco, el presente artículo se propone realizar un repaso por las principales demandas y reivindicaciones del bloque BRICS a lo largo de estos diez años, puntualizando en las reivindicaciones sobre la construcción de un orden mundial multipolar, la reforma de las instituciones de gobernanza global y la necesidad de una nueva arquitectura financiera internacional. Enmarcamos el surgimiento del BRICS en un mundo que atraviesa un proceso de transición hegemónica histórico-espacial, en el que se observa un cambio del centro de gravedad del poder mundial desde el occidente hacia el oriente y desde el norte hacia el sur. En este contexto, un conjunto de estados emergentes comienzan a obtener mayor capacidad de decisión autónoma sobre sus políticas de desarrollo, planteándose el desafío de construir un nuevo orden mundial.

Palabras clave: BRICS; multipolarismo; emergentes; nuevo orden mundial; crisis civilizatoria.

\section{DEZ ANOS DO BRICS: CRISE DE HEGEMONIA OCIDENTAL E CONSTRUÇÃO DE UMA ORDEM MUNDIAL MULTIPOLAR}

Entre 14 e 16 de novembro de 2019, foi realizada a XI Cúpula do BRICS em Brasília, o que significou não apenas o décimo aniversário do nascimento formal do grupo, mas também a décima primeira cúpula consecutiva de líderes desde a primeira reunião em Ecaterimburgo, Rússia, em 2009. Nesse contexto, este artigo pretende revisar as principais demandas do bloco BRICS nesses dez anos, apontando as reivindicaç̃̃es sobre a construção de uma ordem mundial multipolar, a reforma das instituições de governança global e a necessidade de uma nova arquitetura financeira internacional. Enquadramos o surgimento do BRICS em um mundo que passa por um processo de transição histórico-espacial hegemônico, no qual há uma mudança no centro de gravidade da potência mundial do oeste para o leste e do norte para o sul. Nesse contexto, um conjunto de estados emergentes começa a obter maior capacidade autônoma de tomada de decisão sobre suas políticas de desenvolvimento, colocando o desafio de construir uma nova ordem mundial.

Palavras-chave: BRICS; multipolarismo; emergentes; nova ordem mundial; crise civilizacional.

\section{TEN YEARS OF THE BRICS: WESTERN HEGEMONY CRISIS AND CONSTRUCTION OF A MULTIPOLAR WORLD ORDER}

Between November 14 and 16, 2019, the XI BRICS Summit was held in Brasilia, which meant not only the tenth anniversary of the formal birth of the group, but also the eleventh consecutive Summit of

1. Investigador en el Instituto de Investigaciones en Humanidades y Ciencias Sociales, Universidad Nacional de La Plata (UNLP) y CONICET (IdIHCS) y en el Centro de Investigaciones en Política y Economía (CIEPE). Correo electrónico: <jsschulz@gmail.com>. 
leaders since the first meeting in Yekaterinburg, Russia, back in 2009. In this context, this article intends to review the main demands and demands of the BRICS block over these ten years, pointing out in the claims on the construction of a multipolar world order, the reform of global governance institutions and the need for a new international financial architecture. We frame the emergence of BRICS in a world that is going through a process of hegemonic historical - spatial transition, in which there is a change in the center of gravity of world power from the west to the east and from the north to the south. In this context, a set of emerging states begin to obtain greater autonomous decision-making capacity over their development policies, posing the challenge of building a new world order.

Keywords: BRICS; multipolarism; emerging; new world order; civilizational crisis.

JEL: F50.

Data de envio do artigo: 27/2/2020; Data de aceite: 17/4/2020.

\section{INTRODUCCIÓN}

Entre el 14 y el 16 de noviembre de 2019 se llevó a cabo la XI Cumbre del BRICS en Brasilia, lo que significó no sólo el décimo aniversario del nacimiento formal del grupo, sino también la on ceava Cumbre de mandatarios consecutiva desde la primera reunión en Ekaterimburgo, Rusia, allá por 2009. Sin embargo, el término BRICS ${ }^{2}$ data de algunos años antes, y es importante considerarlo para entender el contexto y los objetivos de su surgimiento, y las mutaciones en sus demandas y reivindicaciones.

El término BRIC aparece por primera vez en noviembre de 2001, cuando el economista Jim O’Neill, por entonces jefe de investigación económica global en la sede londinense de la banca de inversiones Goldman Sach, publicó el Boletín Económico no 66 (O’Neill, 2001). En el documento, O’Neill expuso la caracterización de la Goldman Sachs sobre el estado financiero global a comienzos del nuevo siglo, destacando el proceso de crecimiento de las "economías emergentes" quienes, afirmaba, superarían en un corto plazo, en términos del volumen de su PBI, a las potencias englobadas en el G7 (Alemania, Canadá, Estados Unidos, Francia, Italia, Japón y Reino Unido) y serían las encargadas de liderar el crecimiento global en los años subsiguientes. El artículo se titulaba Building better global economic $B R I C$, haciendo un juego de palabras con las iniciales de Brasil, Rusia, India y China y el término inglés "brick" (ladrillo), para señalar que estos países serían los "ladrillos" sobre los que se sustentaría la economía global en el futuro. La Goldman Sachs presentaba a los BRICs resaltando sus variables económicas y financieras particulares de cada país, además de hacer referencia al tamaño de sus territorios (en conjunto el $30 \%$ de la superficie mundial), su población ( $42 \%$ de la población

2. El acrónimo originalmente incluía a Brasil, Rusia, India y China, por lo que se denominaba "BRIC". Las dos primeras Cumbres del bloque en 2009 y 2010 tuvieron esta misma composición. En 2011, cuando los cuatro países acordaron la incorporación de Sudáfrica, el mismo pasó a denominarse "BRICS". En sentido, en el presente trabajo, cuando utilicemos "BRIC" O "BRICs" estaremos haciendo referencia al bloque entre 2001 y 2011, mientras que cuando hablemos del bloque luego del 2011 utilizaremos "BRICS". 
mundial) y de ser altos receptores de inversión extranjera directa (IED). Para 2001, cuando O'Neill publicó su informe, los cuatro países se encontraban entre las once economías más grandes del planeta, medido en términos de PBI Paridad del Poder Adquisitivo - China ( $\left.2^{\circ}\right)$, India (4ํ), Brasil $\left(7^{\circ}\right)$ y Rusia $\left(11^{\circ}\right) .^{3}$

El término "BRIC", entonces, no apareció como respuesta a un vacío analítico en las ciencias sociales o como una aplicación de la teoría de las relaciones internacionales, sino como una acción política de la Goldman Sachs para identificar nuevos mercados para sus grupos económicos y financieros y alentar inversiones que reditúen en mayores tasas de ganancia ${ }^{4}$ (Turzi, 2011b). La banca, en este sentido, utilizaba el término en plural (los "BRICs") señalando que, más allá de sus características comunes, cada mercado tenía su propia estructura de crecimiento y desarrollo (Schulz, 2016).

En este marco, entre 2001 y 2006, el término "BRICs" solo fue utilizado como categoría de análisis para los estudios económicos y financieros sobre el estado del mundo en los inicios del siglo XXI; estos países, afirmaban los analistas, eran los que contrapesaban el descenso del PBI mundial producto del estancamiento de las economías desarrolladas profundizado a partir de 1999-2001. En 2003, en este sentido, otros dos economistas de la Goldman Sachs (Wilson y Purushothaman, 2003) volvieron a hacer referencia a este conjunto de países afirmando que, para 2050, China e India encabezarían el ranking de proveedores globales de tecnología y servicios, mientras que Brasil y Rusia, por su lado, se posicionarían como los principales proveedores mundiales de materias primas y alimentos. Es decir, la Goldman Sachs no solo indicaba cuáles eran los mercados rentables para invertir, sino que indicaba también en que ramas de la economía había que direccionar las inversiones. A su vez, en los informes de la Goldman Sachs, los economistas de la banca remarcaban la necesidad de que estos países mantuvieran una política de apertura de los flujos comerciales y financieros, acompañados de un contexto macroeconómico estable con baja inflación, como condición de posibilidad para lograr un desarrollo exitoso. La apertura al comercio y la inversión extranjera directa, sostenía la banca, proporcionaría accesos a los insumos importados, nuevas tecnologías y mayores mercados; y, posteriormente, realizaban una advertencia, afirmando que "cada uno de los BRICs se enfrenta a retos muy importantes para el mantenimiento de su desarrollo. Esto significa que existe una posibilidad importante de que nuestras proyecciones no sean cumplidas, ya sea por una mala política interna o por mala suerte" (Wilson y Purushothaman, 2003).

3. Según datos del Banco Mundial. Disponible en: <https://datos.bancomundial.org/indicador/NY.GDP.MKTP. PP.CD?end=2008\&most_recent_value_desc=true\&start=2001>.

4. Una aclaración que creemos importante realizar es el hecho de que la Goldman Sachs, así como otras Bancas de Inversión, suelen realizar agrupamientos de países conformando siglas de manera periódica en sus informes y boletines económicos (CIVETS, MIST, EAGLES, etc.). En todos estos casos, los agrupamientos fueron realizados como una estrategia para la redirección de sus inversiones más que como una categoría de análisis geoestratégico (Schulz, 2016). 
"Mala política interna", se entiende, significaba no seguir las recomendaciones de la Goldman Sachs.

Recién en 2006 los propios presidentes de los países aludidos comenzaron a utilizar por motus propio el término "BRICs". En el marco de la 61ํㅗ Asamblea General de las Naciones Unidas, los cancilleres de los cuatro países acordaron incorporar el concepto BRIC a las categorías de política exterior, remarcando la necesidad de afianzar la cooperación mutua. ${ }^{5}$ Entre mayo de 2008 y marzo de 2009, a su vez, hubo reuniones de Ministros de Finanzas de los países miembros del bloque, los cuales adoptaron declaraciones conjuntas sobre los problemas económicos mundiales, incluyendo propuestas alternativas para superar la crisis financiera global. ${ }^{6}$

La primera Cumbre de presidentes del BRIC se realizó en junio de 2009 en Ekaterimburgo, Rusia. Allí, Luiz Inácio Lula da Silva, Dmitri Medvedev, Manmohan Singh y Hu Jintao, presidentes de Brasil, Rusia, la India y China respectivamente, afirmaron que

estamos comprometidos a avanzar en la reforma de las instituciones financieras internacionales, a fin de reflejar los cambios en la economía global. Las economías emergentes y en desarrollo deben tener una mayor voz y representación en las instituciones financieras internacionales (BRIC, 2009).

En Ekaterimburgo, los presidentes del BRICs manifestaron explícitamente la necesidad de establecer nuevas reglas de juego globales, criticando abiertamente el orden mundial unipolar, basado en la especulación financiera, la resolución de los conflictos internacionales mediante la intervención bélica externa y el sometimiento político y económico a los países periféricos por parte de las potencias centrales.

A partir de allí, los BRICS realizaron cumbres sucesivas en Brasilia-Brasil (2010), Sanya-China (2011), Nueva Delhi-India (2012), Durban-Sudáfrica (2013), Fortaleza-Brasil (2014), Ufa-Rusia (2015), Goa-India (2016), Xiamen-China (2017), Johannesburgo-Sudáfrica (2018) y Brasilia-Brasil (2019). En todas ellas, los miembros del bloque afirmaron que luego de la crisis financiera de 2008 el mundo había cambiado, enfatizaron la necesidad de una transformación en las instituciones mundiales, manifestando su apoyo a un orden mundial multipolar, resaltaron el papel del G20 como el principal foro de coordinación económica internacional y de cooperación entre los Estados, y destacaron su papel central en la lucha contra la crisis. Por otro lado, hicieron un llamado a reformar integralmente la Organización de las Naciones Unidas (ONU), para que sea un organismo "más eficaz, eficiente y representativo, que pueda hacer frente a los desafíos globales de hoy en día”, y

5. Ver Coordination among Foreign Ministers, disponible en: <http://www.brics6.itamaraty.gov.br/about-brics/history/ coordination-between-foreign-ministers.>.

6. Disponible en: <archive.kremlin.ru/eng/articles/bric_1.shtml>. 
reclamaron "la urgente necesidad de abordar el déficit de legitimidad del FMI y el Banco Mundial"; 7 en este sentido, reclamaron "un cambio sustancial en la votación poder a favor de las economías emergentes y los países en desarrollo para llevar su participación en la toma de decisiones de acuerdo con su peso relativo en el mundo económico". Además, los BRICS afirmaron su intención de "contribuir de manera significativa al desarrollo de la humanidad y el establecimiento de un mundo más equitativo y justo", resaltando además que "el Siglo XXI debe estar marcado por la paz, la armonía, la cooperación y el desarrollo científico". ${ }^{8}$ Manifestaron también su preocupación ante los conflictos armados en Medio Oriente, Libia, África del Norte y en las regiones de África occidental, y llamaron a la comunidad internacional comprometerse con "lograr la paz, la estabilidad, la prosperidad, el progreso y la dignidad en el mundo de acuerdo a las aspiraciones legítimas de su pueblos". ${ }^{9}$ Por otro lado, se exhortó a las potencias globales a resolver la crisis nuclear iraní mediante negociaciones diplomáticas y se criticó duramente la presión de la OTAN ejercida sobre Irán. Además, llamaron a resolver mediante el diálogo el conflicto armado en Siria, rechazando cualquier tipo de intervención militar internacional y reclamando que se respete la soberanía de estos países.

En abril de 2011, durante la tercera Cumbre BRIC en la ciudad de Sanya, al sur de China, se produce un hecho significativo para el bloque: la incorporación de Sudáfrica como miembro pleno del grupo (a partir de ahora, llamado BRICS). Si bien en la reunión del G20 desarrollada en noviembre de 2010 en Seul los presidentes de Rusia y China ya habían anunciado la unión de Sudáfrica al bloque, la formalización de este hecho se realizó en Sanya.

La incorporación de Sudáfrica generó sorpresas en buena parte de la literatura académica, ${ }^{10}$ ya que los estándares de $\mathrm{PBI}$, población, crecimiento económico, extensión territorial, de Sudáfrica son poco comparables con el resto de los BRIC; sin embargo, la incorporación de Sudáfrica al bloque tuvo que ver con las estrategias geopolíticas y estratégicas de los restantes miembros del bloque. Por un lado, desde el 2003 Sudáfrica ya mantenía estrechas relaciones con Brasil y la India a través del

7. Ver Declaración Final de Brasilia, disponible en: <http://sedici.unlp.edu.ar/bitstream/handle/10915/46681/BRICS_Communiqu\%C3\%A9_10_p._.pdf? sequence=16>.

8. Ver Declaración de Sanya, disponible en: <http://news.xinhuanet.com/english2010/china/2011-04/14/c_13829453.htm>. 9. Op. cit.

10. El hecho de incorporar formalmente a Sudáfrica al grupo suscitó cuestionamientos y críticas negativas desde distintos sectores, inclusive desde los propios "ideólogos" del acrónimo, la Goldman Sachs. En un artículo publicado en el periódico The Guardian, Jim O'Neil afirmó que "no tiene sentido incorporar a Sudáfrica a los BRIC", ya que otros países como Nigeria tenían mejores indicadores macroeconómicos para ser parte del grupo (South Africa gains entry to Bric club, Diario The Guardian, 19/4/2011). 
Foro Trilateral IBSA, ${ }^{11}$ mientras que la cooperación entre China y Sudáfrica había crecido exponencialmente a partir del 2000, llevando al gobierno chino a elevar el nivel de relaciones entre ambos países al de "asociación estratégica integral". Por otro lado, como señalan Dupuy, Morgante y Margueliche (2014, p. 17), Sudáfrica posee además una ubicación geográfica estratégica, en tanto

su actividad en políticas de defensa se extiende hacia los océanos circundantes. Hacia el oeste, participa activamente en maniobras navales con países del Atlántico Sur (Brasil, Argentina). Hacia el este, extiende su presencia sobre el océano Índico, área de expansión de la India y China, sus socios del BRICS. Por último, en dirección meridional, su posición geoestratégica lo convierte en el Estado encargado del control del paso del Cabo de Buena Esperanza, circuito obligado de los grandes superpetroleros y cargueros intercontinentales, impedidos de poder circular por el reabierto Canal de Suez y obligados a navegar próximos a las costas africanas a fin de evitar las tremendas turbulencias de la Convergencia Antártica.

Como señala Morasso (2013, p. 14-19),

la incorporación de Sudáfrica reforzó la superación del BRIC financiero [que había creado originariamente la Goldman Sachs] [...] A diferencia de México, Egipto o Indonesia, Sudáfrica se ha involucrado en temáticas globales y comparte con los BRIC la idea de reformular las estructuras de gobernanza global para adaptarlas a la nueva realidad multipolar.

La V Cumbre BRICS de 2013 en Durban significó la participación, por primera vez, de los nuevos presidentes de Rusia, Vladimir Putín, y de China, Xi Jinping, quienes habían asumido en sus cargos el 7 de mayo de 2012 y el 14 de marzo de 2013 respectivamente. Estas nuevas presencias representaron una aceleración de las políticas del bloque, que se expresarían a partir de 2014 con el lanzamiento en la cumbre de BRICS en Brasil de un Nuevo Banco de Desarrollo (NBD) y un Acuerdo de Reservas de Contingencia (ARC). Estos dos últimos instrumentos, fueron presentados como

las semillas de una arquitectura financiera que intentará por un lado, avanzar en la construcción de un nuevo orden mundial con la mira puesta en ampliar la representación [de los países emergentes] en la toma de decisiones globales y por otro, contrarrestar la unipolaridad del dólar en los mercados financieros internacionales (Noyola Rodríguez, 2014).

11. Ver página oficial: <http://www.ibsa-trilateral.org/>. Algunos autores (Ferreira y Granja, 2014) afirman que el IBSA representa el antecedente inmediato del BRICS, al ser un espacio de coordinación entre Brasil, la India y Sudáfrica que se proponía como objetivo expresar las demandas de los países del hemisferio sur. Si bien este análisis subestima el rol protagónico de China y Rusia para la articulación de los BRICS, el hecho de que Sudáfrica haya formado parte de espacios de coordinación previos que tenían como objetivo el planteamiento de la necesidad de fortalecer la cooperación entre los países emergentes para disputar el nuevo ordenamiento global, planteando la necesidad de un mundo multipolar, es sin duda uno de los elementos centrales para entender el ingreso de Sudáfrica al BRICS. Un estudio detallado sobre la historia y las características del IBSA puede encontrarse en Giaccaglia, C. (2012). 
El objetivo planteado por los BRICS, es que el NBD tuviese el objetivo de movilizar recursos para financiar proyectos de infraestructura y de desarrollo sostenible, no solo en los países miembro del grupo sino también en otros países emergentes. Es decir, el Banco BRICS no se planteó solo como un instrumento para el crecimiento de los países miembros del bloque, sino como intento de brindar acceso al financiamiento internacional a naciones por fuera de los organismos financieros tradicionales para, de esta manera, romper los lazos de dependencia mediante los cuales construyen su hegemonía actores como Estados Unidos o la Unión Europea. Por otro lado, el ARC se estableció como un acuerdo de swaps de monedas de 100.000 millones de dólares, con el objetivo de reducir sustantivamente la volatilidad cambiaria sobre los flujos de comercio e inversión entre los miembros del bloque, y proteger sus economías, incluidas sus monedas, ante posibles ataques especulativos de las grandes potencias globales y grupos económicos financieros transnacionales.

La Cumbre de Brasil de 2014 marcó también la creación del formato "BRICS-Plus", un espacio de coordinación que pretende reforzar los lazos de cooperación Sur-Sur entre países emergentes, y sumar a otros actores a la propuesta del BRICS. El presidente chino Xi Jinping afirmó que el BRICS-Plus sería una plataforma para incrementar la articulación entre los países y civilizaciones para crear un nuevo tipo de relaciones internacionales y construir una comunidad de destino de la humanidad. ${ }^{12}$ En la Cumbre de 2014, se convocó a los países miembros de la UNASUR (participaron los presidentes de Argentina, Bolivia, Chile, Colombia, Ecuador, Guyana, Paraguay, Perú, Surinam, Uruguay y Venezuela). En 2015, en Ufa (Rusia), se organizó una Cumbre conjunta entre los BRICS, la Organización de Cooperación de Shanghái (OCS) y la Unión Económica Euroasiática (UEE), siendo invitados los mandatarios de Afganistán, Armenia, Bielorrusia, Irán, Kazajistán, Kirguistán, Mongolia, Pakistán, Tayikistán y Uzbekistán. En la cumbre india de 2016, se organizó el encuentro BRICS-BIMSTEC (Bahía de Bengala para la Iniciativa Multisectorial Técnica y Cooperación Económica), donde participaron los presidentes de Bangladésh, Bután, Birmania, Nepal, Sri Lanka y Tailandia. En 2017 participaron los presidentes de Egipto, Guinea, México, Tailandia y Tayikistán. En Johannesburgo (2018), fueron invitados el presidente argentino Mauricio Macri (en calidad de presidente pro-tempore del G20), el primer ministro de Jamaica Andrew Holness (en calidad de presidente pro-tempore de la Comunidad del Caribe - CARICOM), el presidente de Turquía Recep Tayyip Erdogan (en calidad de presidente pro-tempore de la Organización para la Cooperación Islámica - OIC) y el Secretario General de las Naciones Unidas, António Guterres. A su vez, también se realizó la "Sesión

12. Xinhua (2019) Xi insta a países BRICS a defender multilateralismo. Publicado en Xinhua el 15/11/2019. Recuperado de: <http://spanish.xinhuanet.com/2019-11/15/c_138555940.htm>. 
Outreach BRICS-África”, donde participaron dieciocho presidentes y primeros ministros africanos.

\section{CRISIS ESTRUCTURAL Y CIVILIZATORIA DEL ORDEN MUNDIAL, CRISIS DE HEGEMONÍAY NUEVA MULTIPOLARIDAD RELATIVA}

Los BRICS, que aparecieron como un acrónimo inventado por una banca multinacional para direccionar sus inversiones, fueron aumentando sus niveles de articulación y coordinación sistemática, lo que les posibilitó ganar grados mayores de poder en el sistema internacional. En el medio, el estallido de la crisis financiera global en septiembre de 2008, sumado al resurgimiento del G20 en noviembre del mismo año como espacio de coordinación global (superando al G7), aceleraron el proceso de coordinación de los países emergentes. Como sostiene Turzi (2011a), la crisis financiera actuó como el catalizador que le permitió a estos nuevos actores, subordinados en la vieja arquitectura financiera, pasar de un agrupamiento basado en la coincidencia de factores a un agrupamiento basado en la coordinación económica y política a partir de la convergencia de intereses.

La crisis financiera global y el ascenso del protagonismo de los estados emergentes en el sistema internacional se enmarca en un proceso de decadencia relativa y crisis de hegemonía de Estados Unidos, que según los abordajes de los teóricos del sistema-mundo (Arrighi, 2007; Wallerstein, 2007), tiene sus inicios en los años ' 70 pero se profundiza luego de la crisis de 2008. Para convertirse en hegemónico un Estado tendría que fundar y proteger un orden mundial que fuera universal en su concepción, es decir, no un orden en el que un estado explota directamente a otros, sino uno que la mayoría de los otros estados puedan encontrar compatible con sus intereses (Cox, 2016). Esto es lo que se empieza a resquebrajarse a partir de la crisis financiera de 2008.

Esta crisis tiene un carácter multidimensional (económica, financiera, ecológica, social y cultural) y alcances globales, siendo la resultante de procesos de disputa de proyectos estratégicos ${ }^{13}$ a nivel global que implicaron la configuración de una nueva territorialidad del poder mundial (Schulz, 2018a). García Linera (2013) sostiene que la devastación capitalista del medio ambiente y la desenfrenada explotación de los recursos naturales, están transformando irreversiblemente el sistema integral de la vida natural del planeta, poniendo en riesgo la existencia de la vida misma, de la naturaleza y del ser humano (como parte de la propia naturaleza). Ubidia (2019), a su vez, señala que el capitalismo financiero neoliberal y salvaje ha puesto a la humanidad en una situación donde

13. El concepto de "proyecto estratégico" implica que una fracción social tiene un grado de desarrollo en su organización económica, política, ideológica, cultural para plantear una determinada "forma de vida" o, como se dice habitualmente, un "modelo" o "sistema" social" (Formento y Merino, 2011). 
para poder crecer en sus ganancias debe imponer un consumismo enfermizo e irracional, en donde cada mercancía (ya sea alimentos, vestimenta, automóviles, teléfonos celulares, etc.) se produce con fecha de vencimiento para forzar en dos o cinco años su recambio, no su reparación, sino lisa y llanamente su obsolescencia. De este modo, la profundización del sistema capitalista en su fase actual, en la disputa por la maximización de las ganancias, conlleva necesariamente a la destrucción del ambiente y la naturaleza. Esto conduce hacia una crisis civilizatoria donde la cultura del descarte y la obsolescencia programada ponen en crisis la capacidad de autoreproducción de la naturaleza y, en consecuencia, la del propio ser humano (Formento, 2016).

En este sentido, Beinstein et al. (2008, parr. 1) sostienen que

vivimos una grave crisis estructural del sistema capitalista y, más aún, una verdadera crisis de la civilización, que puede poner en riesgo la supervivencia de la humanidad. Esa crisis estructural se manifiesta de diversas formas en los distintos continentes, espacios y actividades humanas, $\mathrm{y}$ afecta todos los niveles de la vida y de la sociedad (...) Está claro que se trata de una crisis estructural y no solamente coyuntural, pero, además, de una crisis de la civilización que exige un replanteamiento de parámetros al que la lógica del capitalismo no puede responder.

En este proceso, se observa un cambio relativo del centro de gravedad del poder mundial (Arellanes Arellanes, 2014; Rang, 2014) desde el occidente hacia el oriente y desde el norte hacia el sur, proceso mediante el cual nuevos estados emergentes empiezan a obtener mayor capacidad de decisión autónoma sobre sus políticas de desarrollo. Martins (2014) señala que, en este marco, se produce un paulatino desplazamiento del dinamismo hacia China y el Este Asiático, la ascensión de los regionalismos como nuevo fundamento geopolítico de la economía mundial y de la construcción de un nuevo sistema-mundo multipolar. Este proceso, como veremos más adelante, no es lineal ni homogéneo, ya que no implica la desaparición de los Estados Unidos como potencia que conserva resortes claves de dominación y, a su vez, tampoco implica el desconocimiento de los miembros del BRICS de la totalidad de las estructuras políticas internacionales heredadas.

Es en este marco donde China, Rusia y otros actores van a impulsar propuestas de carácter supraregionales y pluriversales (Grosfoguel, 2008), intentando ampliar su escala y umbral de poder ${ }^{14}$ en el escenario internacional. De este modo, la consolidación del BRICS en tanto espacio de articulación de emergentes de Eurasia, África y América Latina será uno de los objetivos prioritarios de este grupo de países.

14. El concepto de "umbral de poder" está relacionado con la autonomía externa y expresa el poder mínimo que necesita alcanzar un Estado para intentar participar, en calidad de actor principal, en la construcción del orden internacional en un momento determinado de la historia, es decir, para intentar convertirse en un protagonista principal de la historia mundial (Gullo, 2018). 
En este marco, los estados miembros del BRICS comienzan un proceso de articulación y coordinación conjunta que les permita tener más capacidad de presión sobre las potencias centrales del sistema internacional. En este proceso de crisis de la hegemonía norteamericana, se acelera un proceso de multipolarización relativa, es decir, el desarrollo de bloques de poder bajo la forma de Estados-nación continentales que acrecientan su capacidad de desarrollo e influencia global (Formento y Dierckxsens, 2016).

\section{EL PROTAGONISMO DE LOS "EMERGENTES" EN EL NUEVO ESCENARIO GLOBAL}

La categoría de "mercados emergentes" no es nueva, sino que comenzó a utilizarse en los años ochenta y noventa para analizar a los países del este y del sudeste de Asia, resaltando sus altas tasas de crecimiento y su gran potencial económico. El término "mercado emergente" fue utilizado en 1981 por el economista Antoine van Agtmael, quien, según sus palabras, estaba tratando de iniciar un fondo de inversión para el tercer mundo, para invertir en acciones de países en desarrollo, pero estaba siendo rechazado por su alto riesgo. En este marco, el economista afirmó que "por fin se me ocurrió un término que sonaba más positivo y estimulante: los mercados emergentes. 'Tercer Mundo' sugería estancamiento; mientras que 'mercados emergentes' sugería progreso, levantamiento y dinamismo". ${ }^{15}$

La banca de inversión Goldman Sachs, por su parte, en sus informes sobre los BRICs los identifica como mercados emergentes o economías emergentes, destacando por sobre otros indicadores sus importantes tasas de crecimiento de PBI. Como señala Yory $(2014$, p. 30),

el origen de los llamados grupos territoriales emergentes es necesario buscarlo en las motivaciones de los Bancos y de las entidades financieras que, en el contexto de la crisis económica actual, derivada de la propia crisis del modelo económico capitalista neoliberal, no sólo los inventan, tratando de reciclar y salvar el modelo, sino que los promueven - a través de novedosas estrategias de marketing - asignándoles el ostentoso título de "economías del futuro".

Los mercados o economías emergentes, como señalamos, lejos de representar el deseo de las bancas de inversión de presentar nuevos actores que cuestionen el ordenamiento mundial hegemónico, significaba una política de aliento a sus principales accionistas, fondos de inversión y grupos transnacionales, para que redireccionen sus inversiones hacia estos nuevos mercados, es decir, mercados que garantizarín una ganancia asegurada en un contexto de crisis financiera. Pero esto no nos permitiría explicar de por sí la emergencia de nuevos actores reclamando protagonismo mundial. De hecho, entre los nuevos "mercados emergentes", hubo algunos que continuaron subordinados a la lógica financiera del capital angloamericano, mientras que otros comenzaron a articular

15. Ins and outs, The Economist, 18/9/2008. Disponible en: <http://www.economist.com/node/12080703>. 
y posicionarse a favor de un nuevo orden global. Este proceso de emergencia de nuevos actores en el escenario global fue acompañado, en otros casos, por una política de activa participación estatal en la economía, a partir de sostener un paradigma de crecimiento por uno centrado en una economía de mercado, pero con fuerte presencia estatal en el diseño, planificación y ejecución de la política económica y social.

Consideramos importante destacar, entonces, que al interior de cada uno de los emergentes se profundiza una batalla entre los proyectos estratégicos en pugna, donde lo que se pone en juego es cómo interviene cada país ante la crisis: mientras que los grupos financieros transnacionalizados pugnan por subordinarlos al proyecto financiero global, los grupos económicos locales y empresas multinacionales de capital local luchan para que la salida de la crisis se dé mediante la coordinación de los países emergentes con un proyecto autónomo y soberano. En este sentido, Pelfini (2011) identifica dos fuerzas sociales diferentes pugnando al interior de cada uno de los emergentes: por un lado, lo que el autor llama "el clásico establishment" entendido como la clase tradicionalmente dominante y, por el otro, las "elites emergentes" o "grupos estratégicos", las cuales articulan a fracciones de clase y sectores sociales que venían estando subordinados. Teniendo en cuenta esto, vemos nuevamente las dos concepciones, dos formas distintas de pensar los "emergentes". Giaccaglia (2010, p. 57) afirma que

se estiman entonces necesarias algunas precisiones conceptuales, debiéndose diferenciar entre "mercado emergente" y "poder emergente". El primero se asocia a indicadores meramente económicos, especialmente a las tasas de crecimiento nacionales. Poder emergente, en cambio, refiere a aquellos estados que, sobre la base de destacadas capacidades materiales, cuentan con un importante liderazgo en cada una de sus regiones, sumado a un rol destacado en sucesivas y simultáneas negociaciones globales. Es decir, a un alto grado de activismo internacional el cual ha sido definido como el PBI diplomático de un país. Por consiguiente, se considera que la existencia de importantes deficiencias sociales internas no invalida el empleo de esta categoría teórica para hacer referencia a países como India, Brasil y Sudáfrica.

En esta línea, Pelfini (2011, p. 112) utiliza las categorías de potencias, poderes o bloques emergentes:

el primer criterio para definir tal emergencia, y el más fácilmente observable y digerible por los medios de comunicación, es registrar y comparar tasas de crecimiento. Sin embargo, este indicador se relaciona más bien con el concepto de mercado emergente. El término potencia o poder emergente, por su parte, agrega a esto la fortaleza política, medible, en primer lugar, en términos de supremacía militar, pero también de solidez institucional y como capacidad de liderazgo a nivel regional (dimensiones que permiten hablar más propiamente de poder emergente y menos de potencia, que tiene demasiada carga geopolítica y de seguridad). 
En un contexto de profundas transformaciones en el orden internacional actual, la categoría de poderes o bloques "emergentes" nos permite abordar los Estados o bloques regionales con una dinámica de mayor incidencia no solo en la economía global sino también en lo político y en lo cultural, y que no se caracterizan necesariamente por un aumento en el nivel de su "desarrollo" subordinado al sistema político-financiero tradicional, sino criticando su lógica de funcionamiento $y$, finalmente, intentando estructurar un nuevo orden alternativo.

\section{EL PLANTEO DE LA NECESIDAD DE UN NUEVO MUNDO "MULTIPOLAR"}

Mientras que algunos análisis académicos plantean una tendencia hacia una "nueva hegemonía china" o un "nuevo unipolarismo con centro en China" (Actis y Creus, 2018; Tzili Apango, 2012) en este trabajo planteamos la existencia una tendencia a la multipolaridad relativa, es decir, la conformación de múltiples polos de poder, siendo el BRICS una manifestación de este proceso.

Como señalan algunos autores (Gandásegui, 2015; Formento y Dierckxsens, 2018), a pesar del impresionante crecimiento de la economía china durante los últimos años, su PBI es aún el 60\% del PBI norteamericano (medido en términos absolutos), y más en desventaja aun se encuentra si comparamos sus PBI per cápita (u\$s 62.794 contra u\$s 18.236); ${ }^{16}$ además, por capacidad militar y por capacidad de control de los resortes ideológicos y culturales, la diferencia con Estados Unidos sigue siendo importante. A partir de ello, consideramos que no es posible considerar que China pueda competir de igual a igual con los Estados Unidos y establecer un nuevo unipolarismo "con características chinas".

Esta relación se profundiza mucho más con el resto de los países del BRICS. Cada uno de estos países, por separado, resultan insignificantes para luchar contra las grandes potencias globales y desarticulados, este grupo de países quedaría rápidamente subordinado en las estrategias de restauración conservadora de las potencias tradicionales. Es por esto que necesitan crear, potenciar y posicionar globalmente nuevos espacios de coordinación mutua.

Turzi (2017, p. 44) señala que la estructura del sistema internacional es determinada por la distribución de poder que, según afirma, tiene que ver con "cuantos jugadores hay en la mesa del orden mundial". En este sentido, Turzi señala tres distribuciones de podes posibles: la unipolar, cuando un Estado hegemónico concentra el poder económico y militar de manera dominante en el sistema; la bipolar, cuando dos contendientes junto a sus satélites se disputan el mundo en áreas de influencia; y la multipolar, cuando existen más de dos Estados compitiendo por poder e influencia. En el medio entre estos conceptos, diversos autores marcan

16. Banco Mundial. Recuperado de: <https://datos.bancomundial.org/indicador/NY.GDP.PCAP.PP.CD?most_recent_ value_desc $=$ true $>$. 
complejidades que hacen más profunda la idea de polaridad; retomando a Samuel Huntington, algunos autores hablan de "unimultipolaridad", donde desde el punto de vista militar ningún Estado o conjunto de Estados pueden presentarse como oposición efectiva al hegemón (en la actualidad, los Estados Unidos), pero no se puede negar el peso de los nuevos actores emergentes. Otros autores hablan de "interpolaridad", resaltando la combinación entre una redistribución del poder hacia nuevos actores junto con un proceso de interdependencia entre los Estados, producto de la globalización. Por otro lado, hay autores que hablan de "apolaridad", destacando la ausencia de un Estado-nación que pueda llegar a ocupar el lugar de superpotencia (Turzi, 2017, p. 47). Finalmente, existen autores que hablan de una era "no polar", sin Estado-nación hegemónico (Haass, 2008). Actis y Creus (2018), a su vez, señalan la importancia de salir de la perspectiva clásica estadocéntrica a la hora de analizar la polaridad del poder mundial, para dar cuenta de un mundo globalizado con múltiples actores muy poderosos que no están radicados en un país determinado. Las empresas y la banca trasnacional, los grupos terroristas y las organizaciones no gubernamentales internacionales, son actores que suelen quedar al margen cuando se habla de polos de poder en las relaciones internacionales. Retomando los abordajes clásicos de la geopolítica realista, Morgenthau (1962, p. 92) afirmaba que

Estado nacional en sí es (...) un producto de la historia y como tal está destinado a dejar paso con el tiempo a otras formas de organización política (...). Cuando el Estado nacional haya sido reemplazado por otra forma de organización, la política exterior deberá proteger en ese caso el interés de supervivencia de la nueva organización.

En este marco, una de las reivindicaciones que aparece decisivamente en los discursos de los BRICS es la necesidad de dar paso a un nuevo mundo multipolar. Este nuevo orden mundial implicaría la coexistencia de polos de poder que no sólo se limitarían al plano de lo económico-financiero, sino polos-regiones de poder político, cultural y social. De esta manera, mientras que el vicecanciller ruso Serguéi Riabkov afirma que "el BRICS es un símbolo de la formación de un mundo multipolar", ${ }^{17}$ el ex canciller brasileño Celso Amorim, afirmó que "los BRICS colaboran en una cosa muy importante, que es la formación de un mundo más multipolar, menos dependiente de un único grupo o de una única fuente de poder" ${ }^{18}$ En relación a la República Popular China, el concepto de multipolaridad fue introducido oficialmente en el XIV Congreso del PCCh de 1992 por Jiang Zemin, como opuesto a la "hegemonía política del poder”. En el año 2001, Hu Jintao asoció el concepto de multipolaridad con la idea "democratización" del sistema internacional, reclamando igualdad de participación a todos los estados, independientemente de su nivel de desarrollo económico o su sistema político. En el XVI Congreso del PCCh se incorpora oficialmente la necesidad de "democratizar las relaciones internacionales", proponiendo la construcción de un 
mundo "armónico", pacífico y estable (Leguizamón Astudillo, 2018). A su vez, en el Libro Blanco sobre Defensa Nacional en la Nueva Era publicado por el gobierno chino en 2009 (State Council of the People's Republic of China, 2009, p. 4), se afirmaba que "con la llegada del nuevo siglo, el mundo está experimentando enormes cambios y ajustes. (...) La globalización económica y la multipolarización mundial están ganando impulso". Posteriormente, en 2012, Xi Jinping incorporará la idea de conformar una "comunidad de destino compartido para la humanidad" (Schulz, 2019), señalando que "el mundo se ha ido compartiendo en una comunidad en la que el destino de uno está entrelazado con el del otro". ${ }^{19}$

El planteamiento de un mundo multipolar, entonces, implica la necesidad de romper con la unilateralidad en la toma de decisiones globales y asignar un protagonismo de nuevos actores que hasta entonces venían subordinados. En este punto, consideramos importante destacar que estos procesos no son lineales ni acabados, sino que nos encontramos en un momento de transición a la multipolaridad, o como señala Savin (2018) un "momento" multipolar (coyuntural), que puede dar paso o no a una "era" multipolar (estructural).

La construcción del multipolarismo no puede ser entendida solo desde la visión clásica de los Estados-Nación. Los nuevos polos de poder se articulan (o intentan articularse) a partir de la construcción de alianzas y bloques regionales de poder. Como señala Bizzozero (2011), el regionalismo tiene el potencial de ser utilizado por los mayores actores (como aquellos que tienen el status de Estado-región) para generar recursos que incrementen su potencial y le ayuden a posicionarse en la actual, nueva, coyuntura internacional. En este marco, resulta importante ver a Rusia no solo desde su territorialidad estatal, sino conteniendo un conjunto de actores a través de instrumentos políticos y económicos como la Unión Económica Euroasiática (UEEA), creada en el ańo 2000, integrada por Rusia, Bielorrusia, Kazajistán, Kirguistán y Tayikistán; la Comunidad de Estados Independientes, integrada por Ucrania, Bielorrusia, Moldavia, Kazajistán, Kirguistán, Tayikistán, Turkmenistán, Uzbekistán, Armenia, Azerbaiyán y Georgia. Por su parte, en conjunto con China, han impulsado (a partir de 2001) la Organización para la Cooperación de Shanghái, integrada además por Kazajistán, Kirguistán, Tayikistán y Uzbekistán. Asimismo, podemos considerar la estrategia de consolidación de la UNASUR y la CELAC en Latinoamérica como un nuevo polo de poder, en articulación con el resto de los polos.

19. La visión de Xi del mundo: Una comunidad de destino común, un hogar compartido para la humanidad, Xinhua, 16/1/2017. Recuperado de: <http://spanish.xinhuanet.com/2017-01/16/c_135986889.htm>. 


\section{MULTIPOLARISMO Y NUEVA GOBERNANZA GLOBAL}

Varios autores utilizan indistintamente los conceptos de multipolarismo y multilateralismo para referirse a este tipo de relaciones entre estados. Sin embargo, vemos necesario retomar a Sanahuja (2013) para hacer una distinción. El autor señala que el multilateralismo aparece como una reivindicación de distintos actores en el escenario internacional: las administraciones del Partido Demócrata estadounidense, impulsan un "multilateralismo hegemónico", que consistiría en una administración más inclusiva, recurriendo a foros multilaterales para buscar un mayor alcance en sus acciones de política exterior; esto se diferenciaría de las administraciones republicanas, que sostienen una actuación unilateral. Por otro lado, la Unión Europea promueve un "multilateralismo normativo", que actúa como marco de identidad de su propia experiencia de integración, que le da reconocimiento como actor a nivel internacional. En tanto que las nuevas potencias emergentes promueven un "multilateralismo revisionista", que se transforma en una herramienta decisiva para demandar reformas institucionales que promuevan un mayor equilibrio en el orden internacional que le permitan construir alternativas simétricas de cooperación (González del Miño y Anguita Olmedo, 2013, p. 76). Sólo en este último caso es que podemos hablar de un "multilateralismo multipolar", en tanto la exigencia de un ordenamiento global basado en la multilateralidad implica necesariamente el reconocimiento y la coexistencia de varios polos de poder autónomos y soberanos, es decir, una "aspiración, en la medida que apela al imperativo político y moral de un orden legal universal o, en su caso, regional, basado en un corpus de normas de convivencia entre estados soberanos que se reconoce como legítimo" (Sanahuja, 2013, p. 31).

En este marco, los BRICS se caracterizan, por un lado, por un cuestionamiento explícito a lo que consideran un orden mundial unilateral-unipolar, donde existe un solo polo de poder, una sola potencia hegemónica que actúa, de manera unilateral, imponiendo sus decisiones sobre el resto de los países del mundo. Pero, además, se produce un cuestionamiento a las formas de multilateralismo hegemónico sostenidas desde distintos actores políticos y grupos financieros, donde si bien ya no es el Estado-Nación quien impone sus decisiones, la gobernanza global sigue siendo unipolar a partir su organización y estructura económica y de su poder de decisión mayoritario en los organismos multilaterales globales, como las Naciones Unidas, el Fondo Monetario Internacional y el Banco Mundial.

A lo largo de sus cumbres anuales, el BRICS va a posicionarse de tres maneras diferentes frente a la coyuntura mundial actual (Juncal, 2014): por un lado, reclamando a los países desarrollados mayor incidencia en los organismos de crédito internacional (Fondo Monetario Internacional - FMI y Banco Mundial); en segundo lugar, generando iniciativas conjuntas (no exclusivamente en materia económica, sino también política y social) para poder consolidar la articulación entre los socios o comenzar a suplir la falta de respuesta de los países desarrollados 
a los reclamos; y, en tercer lugar, pretendiendo establecer un liderazgo de los países emergentes a nivel mundial, presentándose como "potencias medias" o "potencias regionales" (Morales Ruvalcaba, 2013) que posibilitan la articulación de espacios de poder subordinados en el esquema internacional.

Retomando a Martins (2014), vemos que los BRICS presentan una agenda que propone un giro de las inversiones financieras hacia las productivas, la construcción de marcos intergubernamentales que contemplan al 40\% de la población mundial y ampliarse aún más, el fortalecimiento de un patrón de desarrollo ampliamente apoyado en empresas estatales y pequeñas y medianas empresas, de carácter inclusivo y universalista. A su vez, los BRICS cuestionan lo que Martins denomina la hegemonía atlantista en la economía mundial materializada en el control del sistema de Bretton Woods, el monopolio de las finanzas y la tecnología; e impulsa un patrón de política externa antiimperialista basada en los principios de soberanía, autodeterminación de los pueblos y solución negociada de conflictos.

A lo largo de las Cumbres (Schulz, 2016), las declaraciones de los BRICS hicieron énfasis en la necesidad de fortalecer "los propósitos y los principios de la Carta de Naciones Unidas y el sistema internacional centrado en la ONU" como nuevo modelo de gobernanza internacional multipolar y nuevo modelo de relaciones internacionales, "en oposición al hegemonismo y la política del poder", ${ }^{20}$ el unilateralismo en la toma de decisiones y el injerencismo en los asuntos internos de los Estados.

Sin embargo, a pesar de su peso cada vez más creciente en el tablero económico y político global, los BRICS cuentan con escaso poder de decisión en las instituciones globales tradicionales, lo que se ha convertido en unos de los reclamos más importantes en las declaraciones y documentos públicos del bloque. Instituciones como el Banco Mundial, el Fondo Monetario Internacional y las Naciones Unidas, nacieron como resultante de una correlación de fuerzas favorable a los ganadores de la Segunda Guerra Mundial, y configuraron los cimientos de la vieja arquitectura financiera, económica, política y social, donde los bloques emergentes están claramente subordinados. Luego de la crisis financiera global de 2008, los países emergentes (encabezados por los BRICS) comenzaron a manifestar la necesidad de reformar estas instituciones, para adaptarlas a la nueva correlación de fuerzas.

En cuanto al Fondo Monetario Internacional, las críticas más importantes tienen que ver con dos aspectos: por un lado, un desacuerdo con las políticas económicas y financieras llevadas adelante por el organismo; y, en segundo lugar, 
una crítica a la distribución de "cuotas" de poder en el mismo. En cuanto al peso de las votaciones en el FMI, el mismo ha mantenido una proporción que beneficia a las grandes potencias industrializadas tradicionales, además de otorgarle "poder de veto" a los Estados Unidos ${ }^{21}$ y ser presidido, acuerdo entre potencias mediante, por un miembro designado por la Unión Europea.

Mientras que para 2014 el G7 (Alemania, Canadá, Estados Unidos, Francia, Italia, Japón y Gran Bretaña) concentraba el 43.09\% del poder de voto en el FMI, los países BRICS representaban apenas el $11 \%$ por ciento. En este marco, en distintas declaraciones, los miembros del BRICS afirmaron que "el FMI y el Banco Mundial urgentemente necesitan resolver sus déficits de legitimidad". ${ }^{22}$

En 2010 la entonces directora del FMI, Christine Lagarde acordó impulsar una revisión de las cuotas de voto del organismo, con la finalidad de darle más peso a los nuevos "emergentes". La República Popular China aumentaría sus votos en un 2,2\%, pasando de $3,8 \%$ a $6 \%$ de peso en el organismo, y colocándose como el tercer país con más peso en el Fondo, luego de Estados Unidos y Japón (anteriormente ocupaba el sexto lugar). El porcentaje de votos de Estados Unidos bajaría, aunque de manera casi insignificante (de 16,7\% a 16,5\%, lo que implica conservar el "poder de veto"). El resto de los BRICS también aumentaron sustancialmente su peso: Rusia pasó de 2,3\% a 2,5\%, India pasó de 2,3\% a 2,6\% y Brasil pasó de 1,7\% a 2,2\%. De este modo, Brasil, Rusia, India y China quedan posicionados dentro de los diez países con más peso en el FMI. En contraposición, los más afectados fueron los países europeos, que perdieron peso en el poder de decisión del Fondo: Alemania perdió el 0,5\%, Francia y Gran Bretaña perdieron $0,28 \%$ de sus votos, Bélgica el 0,59\%, Holanda el 0,34\% y Suiza el 0,24\%. El 18 de diciembre de 2015, el Congreso de los Estados Unidos finalmente trató y aprobó la reforma de los poderes de voto en el FMI.

La distribución de poderes en organismos internacionales como las Naciones Unidas no es muy diferente. En la actualidad, la Asamblea General (compuesta 193 estados considerados internacionalmente como soberanos) funciona de hecho como un espacio deliberativo y declarativo, mientras que las decisiones sobre el orden geopolítico son de incumbencia del Consejo de Seguridad, órgano mucho más reducido (quince estados), de los cuales cinco tienen carácter de permanentes y con "derecho a veto" (es decir, es necesario su consentimiento para aprobar cualquier resolución); ellos son Estados Unidos, el Reino Unido, Francia, Rusia y China. ${ }^{23}$ Sin embargo, a pesar de esta estructura de funcionamiento que privilegia la

21. Según el "estatuto" del FMI, para que una decisión sea aceptada debe contar con el $85 \%$ de los votos. De este modo, al tener Estados Unidos el 16,8\% de peso en las decisiones, su voto positivo es indispensable para aprobar una resolución.

22. Declaración Final de la II Cumbre del BRIC en Brasilia, 16/4/2010.

23. Los países ganadores de la Segunda Guerra Mundial. 
visión de las potencias occidentales, son cada vez más frecuentes los casos en que los propios estados con derecho a veto han afirmado que están dispuestos a desconocer las resoluciones del Consejo de Seguridad en el caso de que vayan en contraposición con su política exterior.

A la par de exigir un mayor protagonismo en las decisiones del organismo, los miembros del BRICS también señalan que "las Naciones Unidas [son] el organismo multilateral clave creado para ayudar a la comunidad internacional para preservar la paz y la seguridad internacionales, para proteger y promover los derechos humanos y promover el desarrollo sostenible". ${ }^{24}$ En la Declaración de Fortaleza (2014), los BRICS afirmaron explícitamente que la ONU debía tener un rol protagónico en temas como: desarrollo y crecimiento económico soberano (punto 22), garantizar los derechos humanos (punto 28), prevenir y combatir las actividades delictivas transnacionales (punto 45), la implementación de una estrategia Global contra el terrorismo (punto 48), la delincuencia cibernética (punto 50), el cambio climático (punto 52), el desarrollo sostenible (punto 55) y la lucha contra la corrupción (punto 58); además, también llamaban a las Naciones Unidas a tener un rol protagónico en la tarea de ayudar a mantener la paz y la estabilidad en distintos países, como por ejemplo: apoyar la celebración de elecciones legislativas y presidenciales en Guinea-Bissau, allanando el camino para el retorno a la democracia constitucional (punto 29), ayudar al Gobierno de Malí para estabilizar completamente el país (punto 32), abordar la crisis política y humanitaria en Sudán del Sur (punto 33), abordar los abusos y actos de violencia contra la población civil en la República Centroafricana (punto 34), llevar la paz y la estabilidad la República Democrática del Congo (punto 35), terminar con las invasiones unilaterales de las potencias centrales en Siria (punto 37), contribuir a una justa y duradera solución global del conflicto árabe-israelí sobre la base del reconocido universalmente marco jurídico internacional (punto 38), cooperar con la recuperación económica, política y social de Afganistán (punto 42) y abordar la situación en Ucrania (punto 44).

Con este objetivo, entre 2012 y 2013, todos los países del BRICS aumentaron sus contribuciones al presupuesto de las Naciones Unidas: China incrementó su cuota en $61 \%$, lo que la convirtió en el sexto mayor contribuyente, pasando de 3,2\% a 5,1\% del presupuesto global de la organización; Brasil elevó sus cuotas en un $82 \%$ pasando de $1,6 \%$ a $2,9 \%$; en tanto que la India aumentó su contribución en un $24 \%$.

Otra de las instituciones donde los BRICS dan la disputa por un nuevo ordenamiento global es la Organización Mundial del Comercio (OMC). Cabe recordar que la participación de China en la Organización es sumamente 
reciente, ya que su ingreso a la misma se dio recién el 11 de diciembre de 2001; ${ }^{25}$ este hecho, abrió las condiciones de posibilidad para la llegada de las inversiones extranjeras directas que mencionamos más arriba, ya que eliminó o moderó las trabas que la República Popular China tenía hacia las inversiones extranjeras. Asimismo, el ingreso de China a la OMC también posibilitó que el país dispusiera de mercados para colocar sus inversiones. El reingreso de Rusia a la OMC, a su vez, se produjo en agosto de 2012.

El ingreso de China y Rusia a la OMC profundizóla disputa por la arquitectura económica y financiera global frente a las potencias desarrolladas, llevándolas al interior del organismo. Esta estrategia de coordinación de los BRICS en el marco de la OMC, tuvo uno de sus puntos más fuertes cuando en 2013 (ya con Rusia en el organismo) consensuaron (y luego finalmente concretaron) la candidatura del diplomático brasileńo Roberto Carvalho de Azevedo como director de la OMC, frente al mexicano Hermino Blanco, apoyado por las potencias del G7.

\section{LA CONSTRUCCIÓN DE UNA NUEVA ARQUITECTURA FINANCIERA INTERNACIONAL}

El planteo de la necesidad de una Nueva Arquitectura Financiera Internacional, en tanto complejo jurídico, institucional y normativo que rige las relaciones financieras y monetarias públicas y privadas a escala internacional, es uno de los ejes articuladores del BRICS para la construcción de un mundo multipolar. La llamada Vieja Arquitectura Financiera Internacional (Páez Pérez, 2011) hace referencia al ordenamiento económico-financiero creado por las potencias vencedoras de la Segunda Guerra Mundial en Bretton Woods, y comprendía la complementariedad entre tres instituciones principales: el Fondo Monetario Internacional, el Banco Mundial y la Organización Mundial del Comercio. La crisis financiera global fue el hecho que aceleró el proceso de convergencia de los BRICS y el planteo de la necesidad de discutir una nueva Arquitectura Financiera Internacional.

La creación del Acuerdo de Reservas de Continencia y del Nuevo Banco de Desarrollo, puso de manifiesto una aceleración de este proceso de disputa por una nueva arquitectura financiera, frente al escaso avance en la reforma de la arquitectura financiera global-unipolar, luego de la crisis de 2008.

Esta lucha en el plano económico desarrollada por los BRICS-emergentes para poner en crisis la arquitectura financiera internacional, se manifiesta también en la batalla por la moneda de referencia global, por poner en cuestión la hegemonía del dólar como principal moneda de intercambio y reserva mundial. En sus diferentes

25. China fue uno de los 23 miembros fundadores del GATT (siglas de General Agreement on Tariffs and Trade, predecesora de la Organización Mundial del Comercio), pero en el año 1949, luego de la Revolución, fue expulsada y reemplazada por Taiwán. En el año 1986, la República Popular China notificó su intención de acceder al GATT, aunque su postulación fue aceptada quince años después. 
Cumbres, los países del bloque hicieron hincapié en la importancia de impulsar las transacciones en las divisas de las naciones integrantes del BRICS, con una infraestructura financiera propia que permita eliminar el uso de monedas externas a las de los países del bloque. Esto constituye no solo un intento de excluir al dólar estadounidense y al euro para reducir costos financieros y cambiarios, sino como una estrategia para logar mayores grados de soberanía.

En este marco, el gobierno chino ha impulsado activamente una política de internalización del yuan, lo que produjo que el mismo se haya convertido ya en la quinta divisa más usada en el mundo. ${ }^{26}$ Con el objetivo de internacionalizar el yuan, el Banco Central Chino ha firmado acuerdos cambiarios de swaps de monedas con 34 Bancos Centrales, con el objetivo de lograr la inclusión del yuan en la cesta de divisas que conforman los Derechos Especiales de Giro (DEG), la divisa del FMI. ${ }^{27}$

El 30 de noviembre de 2015, el FMI aceptó finalmente al yuan para ser parte de la cesta de monedas DEG. La nueva composición de los Derechos Especiales de Giro, asignó al yuan el 10,92\% de su proporción, ubicándolo en tercer lugar, por debajo del dólar y el euro.

A su vez, el gobierno ruso, a través de Kiril Dmitriev, jefe del Fondo de Inversión Directa de Rusia y miembro del Foro Empresarial BRICS, llevó la propuesta de crear una criptomoneda y un sistema de pagos único para las operaciones entre los miembros del bloque. Este sistema de pagos común podría competir con el SWIFT, un mecanismo de comunicaciones establecido en la década del '70, que permite a los bancos realizar transferencias electrónicas entre sí, y que en la actualidad es utilizado por 10.500 bancos en más de doscientos países. Sin embargo, luego de los atentados del 11 de septiembre a las Torres Gemelas, el Departamento del Tesoro norteamericano solicitó la supervisión de todos los pagos que se registraran en el sistema (con la excusa de detectar posibles canales de financiamiento terrorista) por lo que, en la práctica, significó la posibilidad de tener acceso a todos los pagos registrados en el mundo. Por ende, la posibilidad de establecer un sistema de pagos alternativo al SWIFT da a los emergentes mayores grados de independencia y soberanía, además de evadir los controles del Departamento del Tesoro norteamericano (Schulz, 2018b).

26. Por debajo del dólar estadounidense, el euro, el yen japonés y la libra esterlina. Fuente: <http://www. elconfidencial.com/mercados/inversion/2015-04-12/china-no-se-oculta-en-la-guerra-de-divisas-el-yuan-la-nuevaeleccion_756296/>.

27. La cesta de monedas de derechos especiales de giro (SDR) del FMI está integrada por el dólar estadounidense, el yen japonés, la libra esterlina y el euro. La inclusión de una moneda dentro de la cesta de los DEG le da la legitimidad para ser considerada una unidad de reserva internacional automáticamente aceptable, mientras que otras monedas deben cumplir con los requisitos de convertibilidad absoluta para poder tener el mismo estatus. 


\section{LOS PLANTEOS ESCÉPTICOS SOBRE EL BRICS Y LA CRISIS DE LOS EMERGENTES}

A pesar de su fuerte impulso luego de la crisis financiera global de 2008, algunos autores señalan que a partir de 2013 el BRICS inició un proceso de estancamiento económico y político que puso en cuestión los planteos de multipolaridad del bloque. La baja en el ritmo de crecimiento de sus economías, las diferencias internas entre los países miembro y la falta de nuevas iniciativas concretas que tradujeran en política práctica lo que proclamaban en el discurso, hizo que se pusiera en tela de juicio la capacidad del BRICS que encabezar la emergencia de un nuevo orden internacional.

La reducción de la tasa de crecimiento y de las exportaciones de China y de la India que comenzaron a manifestarse desde 2012, con efectos negativos en las balanzas comerciales de países como Brasil, Argentina, Chile, Colombia o Perú, sirvieron de base para sustentar la idea de que nos encontramos en la etapa final de un ciclo de expansión iniciado en 2000, que se manifestaría en la vuelta de los "stop-and-go" que caracterizaron durante décadas a los países subdesarrollados. A partir de esto, en 2008 la propia Goldman Sachs comenzó a hablar de nuevos países que superarían a los BRICS como polos de inversión global, especialmente los llamados "MIST": México, Indonesia, Corea del Sur y Turquía. Esta política se vio reflejada en las inversiones que realizó el grupo: mientras que el fondo de inversión MIST tuvo una rentabilidad del $12 \%$, el fondo de inversión destinado a los BRICS se mantuvo en el $1,5 \% .^{28}$

El periódico norteamericano The Independent, incluso fue más duro con los BRICS; en palabras de su editorialista Chris Blackhurst, afirmó que

el viento fue quitado de sus velas y la idea de que puedan reemplazar a los Estados Unidos parece más lejos que nunca. Su incapacidad de gobernarse a sí mismos, de producir sanas y seguras políticas económicas, de poner sus negocios en un mundo golpeado ha demostrado su fracaso. ${ }^{29}$

La cadena CNN también se manifestó en el mismo sentido: "Los mercados emergentes, largamente vistos como los niños mimados de la economía global, se han desplomado".$^{30}$ Ruchir Sharma, jefe de mercados emergentes de la banca Morgan Stanley, afirmó que los BRICS ya no eran destinos interesantes para la inversión y que, en la actualidad, "mis mejores apuestas son países donde están ocurriendo reformas económicas y donde exista un nuevo liderazgo político. Eso está sucediendo en Filipinas, México y Pakistán”. En otra entrevista, el

28. BRICS vs. MIST. Diario La Razón de México, 1/12/2012

29. It's all over for the Brics countries now - upstarts are taking the initiative, por Chris Blackhurst. Diario The Independent, 19/8/2015.

30. El brillo de los países BRICS se apaga. Diario CNN Expansión, 23/8/2013. 
ejecutivo de la Morgan Stanley afirmó que "los BRIC nunca fueron y nunca serán un bloque económico o político (...) Fueron estrellas inesperadas". ${ }^{31}$

Un dato que nos parece relevante mencionar es el hecho de que, en octubre de 2014, la Reserva Federal norteamericana (FED), comandada por Janet Yellen, ${ }^{32}$ comenzó a implementar el fin del programa de estímulos monetarios (hecho que ya había sido anunciado por ex presidente de la FED, Ben Bernanke en octubre de 2013), una política que consistía en la compra compulsiva de bonos gubernamentales "basura" y de obligaciones hipotecarias que no estaban pudiendo ser pagadas por los deudores, y de préstamos a bajas tasas de interés (que iban del 0 al 0,25\%), que fueron a parar principalmente a los mercados emergentes. Esta medida, que había sido puesta en marcha luego de la crisis financiera de 2008 con la excusa de reactivar la economía de los Estados Unidos, significó la inyección de casi 3,7 billones de dólares a los países emergentes. Como señalan Gobbi y Grande (2013), esta política de "expansión cuantitativa" tuvo tres consecuencias centrales para los mercados emergentes: en primer lugar, significó la entrada de capitales motivados por la búsqueda de rentabilidad asociada al diferencial de tasa de interés; en segundo lugar, produjo la apreciación relativa de sus monedas, debido al efecto devaluatorio sobre el dólar estadounidense; $y$, en tercer lugar, mejoró los términos de intercambio, al aumentar el precio de las commodities a nivel mundial.

A su vez, es importante mencionar que tanto Sudáfrica (2018) como Brasil (2016) sufrieron golpes de estado parlamentarios que significaron recambios presidenciales. Si bien en el caso sudafricano el recambio se realizó entre actores políticos del mismo partido (lo que implicó que no hubiese una modificación sustancial de su participación en el BRICS), en caso de Brasil, tanto con Michel Temer como con Jair Bolsonaro iniciaron un acercamiento hacia los Estados Unidos, aunque sin romper relaciones con China.

Rusia, a su vez, sufrió una agudización de la política de sanciones económicas por parte de los Estados Unidos y de la Unión Europea luego del referéndum que votó la incorporación de la península ucraniana de Crimea a la Federación Rusia, con fuertes impactos en su economía.

31. The BRICS never were and never will be an economic or political bloc. A conversation with Ruchir Sharma, 4/1/2013. Disponible en: <http://janelanaweb.com/novidades/\%C2\%ABthe-brics-never-were-and-never-will-be-aneconomic-or-political-bloc\%C2\%BB-ruchir-sharma/>.

32. Reconocida integrante del Partido Demócrata, Yanet Yellen se desempeño durante la presidencia de Bill Clinton, entre 1997 y 1999, como presidenta del Consejo de Asesores Económicos de la Casa Blanca. 


\section{REFLEXIONES FINALES}

El bloque BRICS representa y expresa las intenciones de las potencias emergentes de construir un nuevo tipo de relaciones internacionales basado en la cooperación mutua, la coexistencia pacífica, el desarrollo con inclusión social, la paz y el respeto por la soberanía territorial. La consolidación del BRICS expresa la propuesta de construcción de un orden mundial multipolar, que pueda superar al unipolarismo constituido luego de la caída de la Unión Soviética en 1991, al injerencismo unilateral sobre los asuntos internos de los Estados, a la guerra como método de solución de conflictos y al neoliberalismo financiero que oprime y somete a pueblos, culturas y naciones.

La reciente Cumbre BRICS celebrada en Brasil permitió consolidar la articulación económica y política de los principales países emergentes y en desarrollo, en el marco de un mundo que atraviesa un proceso de transición hegemónica histórico-espacial, en el que se observa un cambio relativo del centro de gravedad del poder mundial (Rang, 2014) desde el occidente hacia el oriente y desde el norte hacia el sur, proceso mediante el cual nuevos estados emergentes empiezan a obtener mayor capacidad de decisión autónoma sobre sus políticas de desarrollo. Si bien no hay un consenso respecto de los tiempos, los modos y la profundidad de esta transición, podemos afirmar que el orden configurado luego de la segunda guerra mundial se encuentra en crisis.

Once años han pasado entre aquella primera Cumbre en Ekaterinburgo, Rusia, donde en aquel momento los "BRIC" (aun sin la incorporación de Sudáfrica) eran aún un proyecto con futuro incierto. Grandes cambios ha habido desde entonces, no solo en el mundo sino también en los propios países integrantes del bloque. De Lula Da Silva a Bolsonaro en Brasil, de Dmitri Medvédev a Vladimir Putin en Rusia, de Manmohan Singh a Narendra Modi en la India, de Hu Jintao a Xi Jinping en China, los cambios en los gobiernos de los países miembro nos hablan de los mayores o menores impulsos que ha puesto cada administración temporal en el bloque, que sin embargo continúa sosteniéndose y fortaleciéndose a lo largo de los años.

La XI Cumbre de los BRICS manifestó la vigencia del bloque, y su propuesta de transformación de la arquitectura económica, política y cultural internacional. Las principales demandas que dieron vida al grupo continúan vigentes, y fueron expuestas en la Declaración Final del grupo a pesar de la heterogeneidad ideológica de los miembros del grupo: la crítica al proteccionismo, la crítica al injerencismo unilateral y la necesidad de reforma de las instituciones de gobernanza internacional. A su vez, también se sostienen el llamado a garantizar la resolución pacífica de los conflictos internacionales, otorgarle más protagonismo a los países en desarrollo en el Consejo de Seguridad de la ONU, el Fondo Monetario 
Internacional y la Organización Mundial del Comercio, y la apertura comercial con eje en el desarrollo.

A partir del 1 de enero de 2020, la presidencia pro-tempore del BRICS pasó a estar a cargo de Rusia, quien será la encargada de organizar la XII Cumbre del bloque en San Petersburgo, recientemente postergada debido al Covid-19. Según afirmó Vladimir Putin, las prioridades de la presidencia rusa estarán puestas en la lucha contra el lavado de dinero y la financiación del terrorismo, además de continuar expandiendo la asociación estratégica entre los miembros del bloque. En un artículo llamado Asociación estratégica BRICS para la estabilidad global, la seguridad compartida y el crecimiento innovador, el Ministro de Asuntos Exteriores de Rusia, Sergei Lavrov señaló que confiaba "en que en el océano de tormenta de la política mundial, el 'barco' del BRICS seguirá un rumbo constante y contribuirá aún más a mantener la estabilidad internacional y garantizar el crecimiento económico global". ${ }^{33}$

\section{REFERENCIAS BIBLIOGRÁFICAS}

ACTIS, Esteban; CREUS, Nicolás. China y Estados Unidos. Foreign Affairs Latinoamérica, v. 18, n. 3, p. 8-14, 2018. Recuperado de: <www.fal.itam.mx>.

ANGUITA OLMEDO, Concepción; GONZÁlEZ DEL MIÑO, Paloma. Estado y multilateralismo, un enfoque teórico. Transformaciones en una sociedad internacional globalizada. JANUS.NET e-journal of International Relations, v. 4, n. 2, nov. 2013/abr. 2014.

ARELLANES ARELLANES, Juan. Dominación sin hegemonía: una evaluación transdiciplinar de la decadencia hegemónica de Estados Unidos y de la crisis estructural del capitalismo desde el análisis de sistemas-mundo. In: . (Ed.). Memorias del Congreso Internacional El Cambio en la Configuración del Poder Internacional, Centro Anáhuac de Investigación en Relaciones Internacionales (CAIRI), 2014.

ARRIGHI, Giovanni. Adam Smith en Pekín: orígenes y fundamentos del siglo XXI. España. Ediciones Akal, 2007.

BEINSTEIN, Jorge. et al. Documento fundacional del Observatorio Internacional de la Crisis. Revista Herramientas, 2008 Recuperado de: <https:// www.herramienta.com.ar/articulo.php?id=637>.

BIZZOZERO, Lincoln. Contenido y funcionalidad de BRIC y de UNASUR en la política internacional del Brasil. In: BIZZOZERO, Lincoln; CLEMENTE, Isabel (Coord.). La Política Internacional en un mundo en mutación, Montevideo, Ediciones de la Banda Oriental y Universidad de la República, p. 31-45, 2011.

33. TASS (2019) - Russia to work on coordination of states within UN as chair of BRICS in 2020. Publicado en Tass. Russian News Agency el 12/11/2019. Recuperado de: <https://tass.com/economy/1088341>. 
BORON, Atilio. Ha iniciado la declinación de Estados Unidos como potencia hegemónica mundial. Granma, 2020. Recuperado de: <http://www.granma.cu/ cuba/2020-02-14/atilio-boron-ha-iniciado-la-declinacion-de-estados-unidoscomo-potencia-hegemonica-mundial-14-02-2020-18-02-45>.

BRIC. Joint Statement of the BRIC Countries' Leaders. Ekaterimburgo, Rusia, 2009. Recuperado de: <http://en.kremlin.ru/supplement/209>.

BRICS. Declaración Final de la XI Cumbre del BRICS, Brasilia, Brasil, 14 al 16 de noviembre de 2019. Recuperado de: <https:/www.panoramical.eu/birregional/51644/>.

COX, Robert. Gramsci, hegemonía y relaciones internacionales: un ensayo sobre el método. Revista Relaciones Internacionales, n. 31, Grupo de Estudios de Relaciones Internacionales (GERI) - UAM, feb./mayo 2016.

DUPUY, Hector Adolfo; MORGANTE, Martín; MARGUELICHE, Juan Cruz. La República de Sudáfrica: los desafíos de la globalización y del desarrollo africano. Cardinalis. Revista del Departamento de Geografía de la Facultad de Filosofía y Humanidades de la Universidad Nacional de Córdoba, año 2, n. 3, 2014.

FERREIRA, L; GRANJA, L. Los BRICS desde la perspectiva poscolonial. V Congreso Uruguayo de Ciencia Política "¿Qué ciencia política para qué democracia?”. Asociación Uruguaya de Ciencia Política, 7-10 oct. 2014.

FORMENTO, Walter. Geopolítica de la casa común. Los BRICS y Francisco. La Haine, 2016. Recuperado de: <https://www.lahaine.org/mundo.php/ geopolitica-de-la-casa-comun>.

FORMENTO, Walter; DIERCKXSENS, Wim. Geopolítica de la crisis económica mundial: globalismo vs. Universalismo, Ed. Fabro, Buenos Aires, 2016.

(Coord.). La crisis mundial. Continentalismos, globalismo y pluriversalismo. Ed. Fabro, Argentina, 2018.

FORMENTO, Walter; MERINO, Gabriel. Crisis financiera global. La lucha por la configuración del orden mundial. Peña Lillo/Continente, Buenos Aires, 2011. GARCÍA LINERA, Álvaro. 9 tesis sobre el capitalismo. Conferencia dictada en el Left Forum (Foro de la Izquierda), Universidad Pace, Nueva York, 7-9 jun. 2013.

GIACCAGLIA, Clarisa. Condicionantes sociales en el proceso de formación de potencias mundiales: un análisis de los países de IBSA a partir de un recorrido histórico. Revista Relaciones Internacionales, n. 15, GERI - Universidad Autónoma de Madrid, oct. 2010.

. IBSA - India, Brasil y Sudáfrica: una iniciativa de Cooperación Sur-Sur que ya es política de Estado. Argentina y Brasil: proyecciones internacionales, cooperación Sur-Sur e integración. Universidad Nacional de Rosario, 2012. 
GOBBI, Hugo Javier; GRANDE, Julieta. La nueva gobernanza económica internacional. Revista Relaciones Internacionales, n. 45, Instituto de Relaciones Internacionales, UNLP, 2013.

GROSFOGUEL, Ramón. Hacia un pluri-versalismo transmoderno decolonial. Tabula Rasa. Bogotá, Colombia, n. 9, p. 199-215, jul./dic. 2008.

GULLO, Marcelo. Relaciones internacionales. Una teoría crítica desde la periferia sudamericana. Editorial Biblos, Argentina, 2018.

HAASS, Richard. La era de la no polaridad. Nuevo Orden Mundial, 2008. Recuperado de: <http://seminariordenmundial.blogspot.com/2008/09/la-erade-la-no-polaridad.html>.

JUNCAL, Santiago Eduardo. El surgimiento de los BRICS y sus implicancias para el orden global. FLACSO-ISA Joint International Conference, Buenos Aires, 2014.

LEGUIZAMÓN ASTUDILLO, Eduardo. Latinoamérica y la Iniciativa OBOR. Observatorio de la Política China, 2018. Recuperado de: <https://politicachina.org/areas/politica-exterior/latinoamerica-y-la-iniciativa-obor>.

MARTINS, CarlosEduardo. El sistema-mundo capitalistay los nuevos alineamientos geopolíticos en el siglo XXI: una visión prospectiva. In: GANDÁSEGUI, Marco; MARTINS, Carlos; VOMMARO, Pablo (Coord.). Soberanía, hegemonía e integración de las democracias en revolución en América Latina, Quito, Editorial IAEN, 2014.

MORALES RUVALCABA, Daniel Efrén. En las entrañas de los BRIC: análisis de la naturaleza semiperiférica de Brasil, Rusia, India y China. Austral. Revista Brasileira de Estratégia e Relaçóes Internacionais, v. 2, n. 4, p. 147-181, 2013.

MORASSO, Carla Maria. Los intereses de Sudáfrica como BRIC. Revista Conjuntura Austral, v. 4, n. 18, 2013.

MORGENTHAU, Hans. Politics in the twentieth century: the decline of the democratic politics. Universidad de Chicago. 1962.

NOYOLA RODRÍGUEZ, Ariel. Geopolítica del Banco BRICS. Red Voltaire. 2014. Recuperado de: <http://www.voltairenet.org/article184789.html>.

O’NEILL, Jim. Building better global economic BRICs. Goldman Sachs, 2001. (Global Economics Paper, n. 66). Recuperado de: <http://www.goldmansachs. com/our-thinking/archive/archive-pdfs/build-better-brics.pdf>.

PÁEZ PÉREZ, Pedro. Otro modelo financiero ya está en marcha en América Latina. Transnational Institute (TNI), 2011. Recuperado de: <https://www.tni. org/my/node/2802>. 
PELFINI, Alejandro. Élites transformativas vs. reactivas: la tensión entre élites políticas y económicas en sociedades emergentes en Sudamérica. In: PELFINI, Alejandro; FULQUET, Gastón (Coord.). Los BRICS en la construcción de la multipolaridad ¿̨eforma o adaptación?, CLACSO, p. 111-123, 2011.

RAMONET, Ignacio. El nuevo sistema-mundo. Le monde diplomatique, 2011. Recuperado de: <https://mondiplo.com/el-nuevo-sistema-mundo>.

RANG, C. La reconfiguración del poder en la fase global del capitalismo. Revista de Estudios Estratégicos, n. 1, p. 33-44, 2014.

SANAHUJA, José Antonio. Narrativas del multilateralismo: efecto Rashomon y cambio de poder. Revista CIDOB d'Afers Internacionals, n.101, p. 27-54. 2013.

SAVIN, Leonid El momento multipolar. Geopolitca.Ru, 2018. Recuperado de: <https:/www.geopolitica.ru/es/article/el-momento-multipolar>.

SCHULZ, Sebastian. Los BRICS. El surgimiento de un proyecto de nueva arquitectura financiera y de un nuevo mundo multipolar (2009-2014). Tesis de grado. Presentada en la Facultad de Humanidades y Ciencias de la Educación (UNLP), 2016. Recuperada de: <http://www.memoria.fahce.unlp. edu.ar/tesis/te.1226/te.1226.pdf>.

. Aproximaciones al estado de situación geopolítica actual. Nuevos actores, conflictos y escenarios para la construcción de un orden mundial multipolar. Revista Cuestiones de Sociología, n. 19, e065, p. 1-14, 2018 a.

. La construcción de un nuevo sistema monetario y financiero mundial. Del BAII y el Banco BRICS al petro-yuan-oro. IX Congreso de Relaciones Internacionales del IRI, 2018b. Recuperado de: <https://www.academia. edu/40008352/La_construcci\%C3\%B3n_de_un_nuevo_sistema_monetario_y_ financiero_mundial._Del_BAII_y_el_Banco_BRICS_al_petro-yuan-oro>.

Aproximaciones a la noción de "comunidad de destino compartido" en el marco de las transformaciones actuales en el orden mundial. XI Jornadas de Investigación, Docencia, Extensión y Ejercicio Profesional (JIDEEP), UNLP, 2019.

STATE COUNCIL OF THE PEOPLE'S REPUBLIC OF CHINA. China's National Defense in 2008, jan. 2009. Recuperado de: <https://fas.org/ programs/ssp/nukes/2008DefenseWhitePaper_Jan2009.pdf>.

TURZI, Mariano. Mundo BRICS: las potencias emergentes. Capital Intelectual, Buenos Aires, 2011a.

- ¿Qué importancia tiene el BRIC? Revista Estudios Internacionales, Instituto de Estudios Internacionales, Universidad de Chile, n. 168, p. 87-111, 2011b. 
Todo lo que necesitas saber sobre el (des)orden mundial. Ed. Paidós, Argentina, 2017.

TZILI APANGO, Eduardo. Cambio en y del poder mundial. Pax "BRICS"inica. Seminario Nuevos Escenarios Internacionales y BRIC, 2012. Recuperado de: <https://www.academia.edu/11560421/Cambio_en_y_del_poder_mundial_ Pax_BRICS_inica>.

UBIDIA, Abdón. La revolución cultural del neoliberalismo. Rebelión, 2019. Recuperado de: <http://www.rebelion.org/noticia.php?id=251575>.

WALLERSTEIN, Immanuel. La situación mundial frente al declive de Estados Unidos. In: GANDÁSEGUI, Marco (Coord.). Crisis de hegemonía de Estados Unidos, México, Siglo XXI editores, CLACSO, 2007.

WILSON, Dominic; PURUSHOTHAMAN, Roopa. Dreaming with BRICs: the path to 2050. Goldman Sachs, 2003. (Global Economics Paper, n. 99). Recuperado de: <http://www.goldmansachs.com/our-thinking/archive/archivepdfs/brics-dream.pdf>.

YORY, Carlos Maria. El grupo BRIC y el 'efecto roquefort': una aproximación a la noción de región-emergente en el contexto de la globalización. GEOgraphia, v. 14, n. 27 , p. $21-45,2014$. 